\title{
Educação em Direitos Humanos no Ensino Técnico e Profissionalizante: Por uma Cultura de Cidadania no Trabalho
}

\author{
La Educación en Derechos Humanos en la Educación y Formación \\ Profesional: La Cultura de los Ciudadanos en el Trabajo
}

\section{Education on Human Rights in Vocational Education and Training: For a Citizens' Culture at Work}

\author{
Luiz Augusto Ceni ${ }^{1}$ \\ 10ssolz@ hotmail.com, Universidade do Oeste de Santa Catarina.
}

\begin{abstract}
Resumo
Busca-se analisar e fomentar a importância da educação em direitos humanos no ensino técnico e profissionalizante, tendo em vista as novas esferas de labor e a célere ascensão de escolas profissionalizantes, por intermédio de políticas públicas, em todo o território brasileiro. Aprecia-se para tanto a evolução histórica dos direitos humanos e as conquistas dos trabalhadores na clássica luta entre capital e trabalho. Analisar as melhores formas de inserir o tema "educação em direitos humanos" no ensino técnico e profissionalizante, colocando em pauta a melhoria da educação. Por fim, tem-se o intuito de levantar questionamentos, analisando se a inclusão do tema contribuiria para a formação cidadã do trabalhador, cooperando com o desenvolvimento de sua autonomia e a consciência dos valores, em busca da construção de uma sociedade mais justa, solidária e participativa democraticamente.
\end{abstract}

Palavras chave: Educação. Direitos humanos. Ensino técnico e profissionalizante. Cidadania.

\section{Resumen}

Se busca analizar y promover la importancia de la educación en derechos humanos en la enseñanza técnica y formación profesional, con miras a las nuevas esferas de trabajo y el rápido ascenso de las escuelas vocacionales, a través de las políticas públicas, en todo el territorio brasileño. Apreciada por la evolución histórica de los derechos humanos y los logros de los trabajadores en la clásica lucha entre el capital y el trabajo. Analizar las mejores formas de introducir el tema "educación en derechos humanos" en la enseñanza técnica y formación profesional, poniendo en pauta el mejoramiento de la educación. Por último, tiene el objetivo de plantear cuestiones, analizando si la inclusión del tema contribuiría con la formación ciudadana del trabajador, colaborando con el desarrollo de su autonomía y conciencia de valores, en busca de construir una sociedad más justa, solidaria y democráticamente participativa.

Palabras claves: Derechos humanos. La instrucción técnica y profesional. Ciudadanía

\begin{abstract}
This academic paper aims at analyzing and fomenting the importance of human rights' education in the technical and vocational education, in view of new methods of employment and the fast ascension of vocational schools, through public politics, all around Brazilian's territory. For that, is analyzed the historic evolution of human rights and the conquers of workers in the classic fight between work and cash, pointing the importance of protecting these rights. Finally, it aims at questioning and debating, heading to analyze if the inclusion of this subject would contribute with the civic education of the worker, cooperating with the development of his autonomy and consciousness about values, heading to construct a society fairer, more solidary and democratically participative.
\end{abstract}

Keywords: Education; Human Rights; Technical and vocational education; Citizenship. 


\section{Introdução}

O estudo dos direitos humanos é de grande relevância na esfera do Direito, em virtude de sua abrangência e importância. No decorrer da história, os trabalhadores têm sofrido explorações na esfera laboral, o que se deve, muitas vezes, pela falta de informação e educação adequada. Após diversas lutas e reivindicações, as condições laborais têm sido valorizadas, fazendo com que os trabalhadores conquistem novos e melhores direitos e proteções em âmbito mundial. No entanto, com a força do mercado capitalista, novos obstáculos se originam, o que pode dificultar a efetivação dos direitos humanos.

A escola, em seus diferentes níveis e modalidades, assume um papel formador e norteador, para a formação cidadã e democrática das pessoas e este caminho se efetiva obrigatoriamente, pela garantia e afirmação teórica e prática dos direitos humanos. (CANDAU, 1995).

Entretanto, os ditames da ordem econômica, influenciam diretamente nas políticas públicas educacionais no Brasil, fazendo com que a rede de ensino aos jovens e trabalhadores volte-se precipuamente ao meio de produção, repassando pouco ou nenhum conhecimento crítico quanto ao real papel e função que exercem no mercado de trabalho. Dessa forma, criam-se homens aptos ao labor, mas sem um posicionamento consciente de sua função no quadro social, priorizando apenas o fazer, e não a transmissão de conhecimentos. (COUTINHO, 2007).

$\mathrm{Na}$ sociedade contemporânea, as novas exigências evidenciam a necessidade e urgência em garantir maiores conhecimentos. Entretanto, não basta unicamente inserir o indivíduo na escola ou garantir o seu acesso a mesma, é imprescindível reavaliar a essência e finalidade da educação técnica ou profissionalizante quanto ao conhecimento repassado ao aluno e trabalhador, promovendo políticas públicas que ampliem sua capacidade de atuar em prol do Brasil. (SILVA, 2000).

Dessa forma, o presente trabalho faz uma valoração do mundo do trabalho e da educação em direitos humanos, demonstrando de que forma a educação em direitos humanos é capaz de contribuir para a formação cidadã do trabalhador. Fomenta-se o importante papel que a educação possui na criação de uma sociedade mais solidária, formando trabalhadores críticos que, muito além da busca em conceber capital, busquem exercer a cidadania de forma consciente e deliberada. (SOUZA, 2010). 


\section{Direitos humanos}

Os direitos humanos são aqueles direitos inerentes ao homem, por sua própria natureza e pela dignidade que a ela é inerente. Eles explicitam a dignidade humana, assegurando a existência fraterna e igualitária entre as pessoas. Ao serem incorporados no ordenamento jurídico dos estados, os direitos humanos tornam-se direitos fundamentais, assim chamados por serem essenciais à existência de uma sociedade democrática de direito. (PINHEIRO, 2008).

Os Direitos Humanos (DH) não fazem menções exclusivas a uma determinada pessoa, membro de um Estado ou de alguma nação, pelo contrário, relacionam-se estritamente à pessoa humana em toda sua universalidade, pois, trata-se de direitos universais e naturais ao homem e sua existência está acima de qualquer lei, não precisando estar legalmente expressos para serem evocados. Entretanto, após terem sido reconhecidos em tratados e Constituições espalhados pelo planeta, os Direitos Humanos tiveram um inegável e importante avanço civilizatório. (SILVEIRA, 2007).

Filósofos e Juristas como Hobbes, Locke e Kant, defendiam a concepção de Direitos Humanos como sendo direitos naturais, direitos inerentes a todos as pessoas, ou seja, originários na própria natureza humana, existente antes mesmo da formação do Estado, possuindo assim, um ordenamento universal, antecedente e prior ao próprio direito positivado. (BAEZ, 2007). São naturais por sua concepção vinculada à natureza humana, e, por ser anterior e estar acima de qualquer texto normativo, não há necessidade de documento legal para serem evocados. E são universais porque estão inerentes a todos os indivíduos, sem restrições a um determinado local ou determinada povo. (BENEVIDES).

\subsection{A evolução da educação em direitos humanos no Brasil}

Igualmente como na América Latina, no Brasil a Educação em Direitos Humanos teve início nas lutas sociais de resistência cultural às violações aos direitos humanos e serviu como base para o processo emancipador do país, além de conquistas e criações de direitos. (SILVEIRA, 2007).

Devido múltiplos casos de violências e de injustiças sociais no Brasil, afirma-se quase a impossibilidade de relatarmos situações positivas sobre Direitos Humanos, o fático mesmo, é a acumulação histórica de injustiças, necessitando fazer uma viagem desde os primórdios da descoberta do Brasil, século XIV para conceber com maior clareza esse caminho, que teve um 
prefácio bem distante de um conceito de justiça social, basta ver o escasso reconhecimento e respeito dos direitos humanos dos cidadãos. (SILVEIRA, 2007).

Devido à colonização portuguesa, o Brasil desde o seu princípio histórico, foi marcado drasticamente pela desvalorização das pessoas, diferenciando negros, índios ou qualquer outro ser humano inferior aos senhores da terra. Os habitantes primitivos da terra foram os primeiros a sofrerem com o desrespeito e a ganância dos novos colonizadores, os índios foram explorados, escravizados, e por fim, perderam suas terras roubadas. Seus espíritos de liberdade em consonância com o contato especial com a natureza, não foram suficientes para resistir à ambição de riquezas dos colonizadores. (SILVEIRA, 2007).

Durante muito tempo, as intenções portuguesas para a sua colônia em terras tupiniquins tenderam a serem somente o controle e defesa do território, sem quaisquer iniciativas educacionais organizadas e de qualidade - indo de encontro com o que ocorria nas colônias Américas Espanhola e Inglesa, que tiveram acesso ao ensino superior no período colonial, vindo o Brasil obter o acesso ao ensino superior com as primeiras instituições culturais e científicas, logo após a chegada da família imperial ao país. (FAVA, 2014).

Durante os duzentos anos antecessores o ensino formal ficou sob responsabilidade dos jesuítas, pautados na cristianização dos indígenas e na formação do clero. Os jesuítas desembarcaram no Brasil em 1549 e trouxeram nas malas a sua doutrina, os costumes e a religiosidade europeia, além da ordenação e métodos pedagógicos - marcando assim, os primórdios da educação brasileira na pregação cristã e no trabalho educativo. (FAVA, 2014).

Segundo o estudo de historiadores, habitavam no país no ano de 1500 , entre quatro e cinco milhões de índios, no entanto, década após década foram sendo aniquilados, ou pelo forte poder de pólvora ou pelas devastações naturais que garantiam suas subsistências, sobrevivendo somente às tribos mais isoladas e protegidas pela floreta. A valiosa cultura indígena vem sofrendo com pressões de fazendeiros e da sociedade até a atualidade, restando menos de trezentos mil índios. (SILVEIRA, 2007)

Os índios vão morrendo de fome, porque os brancos estão destruindo as florestas e envenenado os rios, além de morrem também de doenças levadas pelo branco, sem que o governo cumpra as obrigações legais de proteger os territórios indígenas e de proporcionar assistência médica os índios. É um genocídio mais ou menos disfarçado, que necessita de algum tempo para se consumar, mas é absolutamente certo. Os “civilizados” estão assassinando os "selvagens”. (SILVEIRA, 2007, p.30) 
É a partir deste período que o Brasil herda o terrífico laurel de país onde reina as maiores desigualdades socioeconômicas de todo o planeta, dando origem aos moldes social divisores da atualidade, divisão estabelecida entre ricos e pobres, empregadores que mandam e escravos ou assalariados cumpridores de ordens. (COMPARATO, 1999).

Tendo em vista, a dificuldade da escravização indígena, os colonizadores deram início à escravidão de negros africanos. A escravidão negra, herança funesta e não só do Brasil, trata-se de uma nefasta tragédia humana, que se apropriava de seres humanos negros nascidos na África, como também, em várias outras partes do planeta. A escravidão teve término oficial no Brasil no dia 13 de maio de 1888, sendo abolida pela princesa Isabel (filha de D. Pedro II), por meio da lei Áurea. Após a abolição da escravatura o país começou a contratar grandes levas de trabalhadores europeus, contratados para o labor no campo. (SILVEIRA, 2007).

\footnotetext{
Há pouco mais de cem anos vivíamos, nesta terra dita de Santa Cruz, no regime da Casa Grande e Senzala. Nossos antepassados defendiam a escravidão como "natural", pois acreditavam, ou fingiam acreditar, em falsas teorias sobre a "inferioridade" dos negros. Tinham, ainda, o apoio espiritual dos que invocavam a diversidade na criação divina para justificar as odiosas desigualdades entre seres humanos. Havia, ademais, uma perversa doutrina econômica que defendia como necessidade imperiosa, a mão-de-obra escrava. (BENEVIDES).
}

A formação de um parque industrial no Brasil, com sede principal em São Paulo, foi construído na passagem final do século XIX ao XX - tendo como mão de obra os trabalhadores europeus, que na grande maioria eram operários emigrados como refugiados econômicos, segundo relato de historiadores e estudiosos da vida econômica do país. Os imigrantes só aceitaram vir trabalhar na área rural pela extrema dificuldade financeira que passavam na Europa e pelo sonho implantando em suas mentes de serem proprietários de suas próprias terras, devido os dizeres que deste lado do mundo havia terras em abundância e sem proprietários. (SILVEIRA, 2007).

Após a chegada dos imigrantes, a grande maioria se deslocou do campo para as cidades em busca de emprego nas indústrias, até porque possuíam vasto conhecimento e experiência, e acima de tudo, consciência de direitos e a luta organizada pelos mesmos. Então se deu o início às ideologias de comunismo e anarquismo nas mentes dos trabalhadores do Brasil, dando maior relevância a influência dos trabalhadores espanhóis e italianos, que desembarcaram na terra tupiniquim no final do século XIX. Assim, surgiram às reuniões 
políticas as associações operárias que antecederam os sindicatos, os fundos de solidariedade e as greves, sendo a primeira greve registrada no Brasil no ano de 1905, na cidade do Rio de Janeiro. (SILVEIRA, 2007).

A primeira República brasileira teve início em 1889 e durou até 1929, concomitantemente com a grande crise econômica, abalando a economia brasileira e mundial. Em 1930, com Getúlio Vargas assumindo a chefia de um governo provisório com a chamada revolução ou o golpe, (SACAVINO, 2009), concedeu-lhe condições para realizar manobras políticas, criando, por exemplo, concessões aos empregadores, executando no Brasil de maneira formal, os direitos dos trabalhadores com base na Carta Del Lavoro, da Itália, conquistando assim, a permanência à frente do cargo de presidente brasileiro durante quinze anos. (SILVEIRA, 2007).

Uma das principais características do período Vargas foi o desenvolvimento da legislação trabalhista, assegurando um mínimo de garantias aos trabalhadores. Entretanto, o aperfeiçoamento da legislação não representou, na prática, o efetivo respeito pelos direitos e a eliminação das injustiças. "Obter o maior lucro possível pagando o menor salário possível" contínuo sendo o lema dos empresários. No período de restabelecimento da ordem democrática no mundo, a partir de 1945, sob influência dos Estados Unidos, com quem o Brasil se tinha aliado na Segunda Guerra Mundial, toda reivindicação operária passou a ser classificada como "subversão comunista" e as Forças Armadas nacionais foram intensamente utilizadas para proteção da ordem, que era, na realidade, a ordem conveniente ao grande capital. (SILVEIRA,2007).

A imprensa e os grandes jornais da época de 1964 tiveram papel fundamental para que ocorresse o Golpe Militar, legitimando a derrubada do Presidente João Goulart e tornando este fato um marco histórico, fechando um período e dando início a uma nova etapa na história brasileira. (SILVA, 2014).

A Ditadura Militar foi marcada pela drástica violação de direitos humanos e pela ruptura das alianças de classe existentes, estabelecendo um novo modelo econômico estabelecido, como também a mudança de ideologias referente os direitos conquistados até esse período. (SADER, 2007). Como visto, pode-se afirmar que os direitos econômicos e sociais do povo brasileiro foram praticamente dizimados de seu cotidiano, além do mais, os direitos políticos, direitos da organização, direito de expressão, o da privacidade e entre outros, no decorrer da ditadura foram sendo violados durante o período ditatorial. 
O golpe militar cortou, drasticamente, os fundamentos desse modelo e desse processo de mobilização social ascendente. Rompeu qualquer tipo de aliança com os trabalhadores, colocando-os, ao contrário, como uma das metas repressivas privilegiadas do novo regime, tratando-os como inimigo, na medida em que suas reivindicações atentariam contra o novo modelo econômico. Este passou a privilegiar claramente as altas esferas do consumo e sua absorção de produtos de luxo, conjuntamente com a exportação, a expensas do mercado interno de consumo popular. $\mathrm{O}$ arrocho salarial foi eixo nessa virada: diminuía fortemente a participação do trabalho na renda nacional e, automaticamente, elevava a taxa de exploração da força de trabalho e, assim, a taxa de lucro do capital. A repressão aos sindicatos, a prisão de líderes sindicais, a proibição da existência da imprensa sindical e opositora, faziam com que a repressão fosse funcional à política favorável ao grande empresariado e contra a massa da população - que vivia de salários e fomentava, até ali, a extensão do mercado interno de consumo. Esse novo contexto histórico combina violação dos direitos econômicos, sociais e políticos de forma intensa como o país nunca havia conhecido. (SADER, 2007, p.77).

Devido às variadas formas de ocupação do território brasileiro, além dos interesses econômicos dos próprios europeus das ricas terras, tudo isso acarretou na formação da sociedade atual, no qual o acesso à riqueza e as desigualdades sociais e de direitos estão estampados na rotina dos cidadãos. A realidade é que o Brasil possui regiões bem diversificadas entre si, onde nas regiões sul e o centro-sul estão bem desenvolvidos, com infraestruturas modernas e dignas, com mais oportunidades de empregos e ascensão social. No entanto, há outras regiões como o norte e nordeste que estão abandonadas, atrasadas, escassas oportunidades de emprego, sem educação de qualidade e infraestrutura precária, isso ocorre não por falta de verbas públicas, mas pelo descaso de seus governantes que semeiam somente o favorecimento pessoal. (SILVEIRA, 2007).

Dando início a década de 1980, período marcado pela redemocratização brasileira, onde o pluripartidarismo e as eleições diretas para governadores contribuíram para a ampla vitória dos partidos opositores ao regime ditatorial, além da consolidação do movimento Direta Já quatro anos depois. Em 1986, elege-se a Assembleia Constituinte, e, em 1988 é promulgada a Constituição Federal - enunciando de forma vigorosa a garantia e direitos civis, políticos e sociais. A Constituição foi apelidada como a Constituição Cidadã - reafirmando o país como uma democracia comprometida com a vasta extensão de direitos aos cidadãos e a todos os setores da sociedade. (SACAVINO, 2009).

Devido às lutas e reivindicações sociais nascidas no período da ditadura, o Brasil vem mostrando nas últimas décadas a sua força social, muito influenciado pelo consenso mundial, no qual estabelecem que os direitos humanos devem ser os princípios basilares e fundamentais para a garantia de uma sociedade livre, harmônica, justa e solidária. Conforme dissertado no parágrafo anterior a Constituição brasileira de 1988, foi elaborada logo após o período ditatorial, sendo a afirmação dos anseios de liberdade e democracia aclamados pela 
nação, além do mais, foi o mecanismo legítimo de consagração com força jurídica, das aspirações por justiça social, e proteção dos direitos humanos da maioria da população brasileira, habituada ser vítimas de uma ordem desigual, condenando-os à exclusão e à violência. (SILVEIRA, 2007).

As exigências sociais aclamadas até então, foram supridas pela Constituição Federal da República (CF) de 1988, no qual foram estipulados em seu texto os direitos fundamentais a toda pessoa humana, além de prever as garantias para a efetivação destes direitos. Afirma-se, que pela quantidade e qualidade de normas beneficiando a população, a Constituição Cidadã se torna a mais democrática já promulgada no país, comparando-se as constituições europeias pós a segunda guerra mundial. (SACAVINO, 2009).

Com a Constituição Federal de 1988, instituidora do Estado Democrático de Direito, o Brasil ampliou processos de ratificação, criando no nível interno importante mecanismo nacional de proteção aos direitos humanos.

Após o período ditatorial, outro momento marcante ocorreu no processo político educacional brasileiro, na regência do presidente Fernando Henrique Cardoso, logo no inicio do seu mandato, no ano de 1996, criou a Lei de Diretrizes e Bases da Educação Nacional. (BRASIL, 1996).

Porém, a política no Brasil vem vivendo momentos contraditórios, onde de um lado durante alguns anos a população sente ódio e repulsa pelos políticos, haja vista seguidos casos de corrupção, e em especial o Congresso. Por outro lado, a consciência da população vem expandindo e compreendendo a importância de participarem ativamente na vida política, pois é a maneira mais eficiente de se alcançar a consolidação efetiva dos direitos conquistados e exercer a democracia. (SACAVINO, 2009).

\subsection{Educação do trabalhador}

Entender a relação entre trabalho, ciência, tecnologia e cultura significa conceber o trabalho como princípio educativo. O trabalho como princípio educativo significa que o ser humano é produtor de sua realidade, se apropria dela e pode transformá-la, ou seja, somos sujeitos de nossa história e de nossa realidade e o trabalho é a primeira mediação entre o homem a realidade material e social. Por certo, o trabalho também se constitui como atividade econômica, pois produz riquezas e satisfaz necessidades, logo na atual sociedade o viés econômico tornou-se fundamento da profissionalização. No entanto, na integração entre trabalho, ciência e cultura, a profissionalização se opõe como simples formadora de indivíduos aptos ao mercado de trabalho, no qual deveria fornecer a compreensão das 
dinâmicas produtivas das sociedades modernas, mostrando as suas conquistas e adversidades, e ir além, em habilitar os indivíduos para exercer profissões autônomas e com pensar crítico. (BRASIL, 2007).

Ter o ensino escolar com o princípio de formar cidadãos críticos e ativos trata-se de uma ideia recente na educação brasileira. Com novas propostas enfatizando a importância da escola em formar alunos que assimilem e compreendam o significado de cidadania e façam proveito disto. Tal ideologia foi defendida antigamente pelo estudioso Antonio Gramsci, que primava à escola como instrumento para a educação de cidadãos. (SOUZA, 2010).

Consoante ao pensamento Gramsciano, a educação faz parte constante do processo de formação do homem e a escola é o caminho fundamental para a construção de uma educação humana que compreenda a disciplina no agir, onde o ser humano aprenda na medida em que faz escolhas, e, essas escolhas transformam e moldam a sociedade que lhe cercam. (FORTUNATO, 2009).

Formador da ideologia "escola do trabalho", Gramsci idealizava a escola como formadora da nova geração de produtores, a fim de que preparasse técnicos que fossem além de apenas executores mecânicos, mas dominadores de suas artes ao cultivar o saber sobre a técnica e todas as suas possibilidades. Desta forma, a escola havia de ser o viés para concretizar uma linha entre teoria e prática, respeitando a individualidade de cada aluno, que é fruto da interação entre indivíduos e entre estes com a natureza. É neste sentido, que a relação do homem com a natureza se dá pelo trabalho e pela técnica, que além do conhecimento fabril se faz presente o conhecimento intelectual filosófico e científico, no qual a técnica torna-se expressão desse conhecimento. (FORTUNATO, 2009).

É importante e fundamental, pensar a questão sobre a Educação Profissional Técnica de Nível Médio, tendo em vista o cenário econômico nacional, em particular os impactos da política econômica sobre a educação e o emprego, produção e renda. Sendo a política de Educação Profissional parte de um conjunto de políticas públicas de educação, notam-se também articulações políticas no âmbito econômico, vindo a Educação Profissional a se tornar instrumento político de equilíbrio das condições no quadro dos setores produtivos do trabalho. (RUSSO, 2006).

$\mathrm{Na}$ incessante luta histórica dos trabalhares, almejando o equilibro salarial perante a lei da oferta e da procura de mão de obra, atualmente o avanço tecnológico das grandes empresas acarretou em prejuízos às contratações de trabalhadores, em razão de as empresas ficarem estritamente vinculadas às suas produções e lucratividade, isto é, devido ao aumento do produto marginal do trabalho, e por consequência disto, aumento da demanda de mão de obra. 
Logo, isso acarreta na diminuição dos níveis salariais, tendo-se a necessidade de trabalhar mais e acabar recebendo salários inferiores. (SILVEIRA, 373).

Grande parte do estimado equilíbrio entre o labor e a estabilidade do capitalismo estão inseridas pelo papel da OIT e das legislações internas, que lhe asseguram a promoção da dignidade trabalhadora. Todavia, maior proteção a dignidade é dada ao trabalhador que se submete as ordens e trabalha para outrem em troca de remuneração. (CECATO, 2007).

Partindo da premissa de que um maior grau de escolaridade e instrução gera uma melhor condição de empregabilidade, surge a busca por uma maior diversidade na natureza de ofertas empregatícia, e por consequência disto, o mais capacitado obterá uma renda laboral mais elevada do que o trabalhador sem instrução. É de ciência de todos que a educação, conforme comprova a historicidade, sempre foi destinada para a elite, tendente a acumular mais riquezas, já que o acesso à educação não se dá em igualdade de oportunidades a todas as classes no mercado. (COUTINHO, 2007).

Por certo, aquele que adquiriu melhor nível intelectual por ter frequentado mais instituições de ensino dispõe de mais vantagens e oportunidades daquele que não a conseguiu. Todavia, a questão essencial é que não há lugar para todos na conjuntura atual do desenvolvimento, onde projetos educacionais, como por exemplo, o EJA, tem a necessidade de moldar-se ao mercado de trabalho, acarretando na perca de seu papel fundamental, que seria: a de formar cidadãos, da luta pela evolução da qualidade do ensino e a preocupação com o lado humano da esfera laboral e não apenas na lucratividade do mercado. (VALLE, 2011).

Diante disto é concludente afirmar que a educação no ensino superior é privilégio de uma elite pensante, cabendo as classes mais pobres somente preparação de mão de obra para a produção. Até porque é significativo o aumento em oportunidades de trabalhos, porém com remunerações inferiores e serviços mais precários, sem a necessidade de diplomas. Cabe ressaltar, ademais, que hoje em dia a formação em nível superior já não é garantia de melhores condições de emprego e salários. (COUTINHO, 2007)

Para Gramsci, tinha-se a necessidade e urgência em intervir na estrutura da escola formativa, tendo em vista não haver o viés democrático estabelecido, pois gerava a permanência das diferenças sociais. Para eliminar essa emboscada, deveria se evitar a hierarquia e os variados tipos de escolas profissionais, realizando uma única escola preparatória, trilhando e conduzindo o jovem para facilitar sua escolha profissional, tornandoo um envoltório de conhecimento prático, tendo a capacidade de pensar, de estudar, de dirigir ou de controlar quem dirige. (GRAMSCI, 2009) 
Conceber uma integração de formação humana que é basilar a integração de todas as dimensões da vida, como o trabalho, a educação, a ciência e a cultura, no processo formativo educacional. Esta ideologia pode conceber e orientar a educação geral e a profissional simultaneamente, e o caminho para atingir esta formação é a formação politécnica dos trabalhadores, ofertando-lhes o devido conhecimento e compreensão das relações sociais do setor produtivo, o processo histórico do mundo laboral, possibilitando aos indivíduos a captação real do processo histórico de produção cientifica, tecnológica e cultural das camadas sociais, propiciando a expansão do saber em prol da transformação das potencialidades e dos sentidos humanos. (CIAVATTA, 2011).

\subsection{Educação e cidadania}

Cidadania é um conceito utilizado influentemente em sua significação liberal burguesa. Corrobora-se na visão de homem de direitos naturais, sendo que tais direitos advêm da historicidade social vivenciada pela própria construção das gerações de direitos humanos. Pela linha histórica, as gerações se evidenciam a partir dos direitos civis, posteriormente nos direitos políticos e, apesar de estudiosos afirmarem o avanço para além da terceira geração, conclui-se a geração dos direitos sociais. (PACHECO, 2012).

A cidadania sucintamente resumida atinge sua completude somente quando as três dimensões dos direitos humanos ou naturais forem concebidas na vivência social. Essa plenitude cidadã ou democrática não ocorre atualmente, tendo em vista os ditames capitais em que opera a estrutura social, onde ocorre uma contradição econômica quanto a socialização do trabalho e a privatização dos meios de produção e também uma contradição política, com uma proposta democrática de soberania popular que trilha unida com a privatização do poder. (PACHECO, 2012).

Segundo Dallari, cidadania está intrinsecamente ligada às condições básicas para exercer ativamente a vida pública, a qual exige que se assegurem os direitos fundamentais aos indivíduos, ou melhor, a cidadania tem o objetivo de expressar um conjunto de direitos que torna a pessoa apta para participar das decisões políticas de sua nação. (DALLARI, 1998).

Segundo a historicidade, o significado de cidadão parte da ideologia de igualdade política e da participação de todos. Esta ideia surge na Grécia antiga e foi revivida na Revolução Francesa. (DALLARI, 2000).

No livro "Cidadania, Classes social e Status", o autor Marshall, com base no contexto político e histórico ocorrido no século XX na Inglaterra, concebe e relaciona os direitos e 
deveres dos cidadãos com o conceito de cidadania às três gerações de direitos: os civis, os políticos e os sociais. (MARSHALL, 1967).

Como afirma Norberto Bobbio: "a democracia é a sociedade dos cidadãos, e os súditos se tornam cidadãos quando lhes são reconhecidos os direitos fundamentais." (BOBBIO, 1992).

Uma promessa não cumprida é a educação para a cidadania, pois as novas exigências surgidas na sociedade colocam em pauta que não seria unicamente garantir ao indivíduo o acesso à escola, mas sim, há a necessidade de reavaliar a essência e finalidade da educação, quanto aos seus intuitos e seu papel social. (SILVA, 2000).

A educação é requisito essencial para criar e moldar uma sociedade democrática e cidadã. Entretanto, há limites impostos pela globalização e os massivos e excessivos instrumentos de informações, que por consequente, impedem a concretização dos direitos políticos, civis e sociais, que permitem inserir o indivíduo de modo ativo na sociedade que lhe cerca. (SILVA, 2000).

Por certo, a educação é fonte primordial para que ocorra transformações sociais, conforme constata Vitor Henrique Paro, seriam no mínimo dois motivos que confirmam o poder do papel da educação: o primeiro seria o lado pedagógico, devido à luta política da classe trabalhadora na tentativa em desarticular o poder da classe burguesa, e a outra fonte seria o caráter da apropriação do saber histórico acumulado. Conforme se apropriam deste saber, compreendem o seu papel social de cidadãos ativos, e tornam-se independentes. (PARO, 1999).

No Brasil, inúmeros foram as transformações e mudanças ocorridas desde a Constituição Política do Império liberal, em 1824, que, em seu art.179 XXXII, assegurou pela primeira vez, a instrução primária gratuita a todos os cidadãos, (COUTINHO, 2007), até a promulgação da atual CF de 1988, que enunciou a educação como direito de todos e dever do Estado e da família, aplicando no âmbito jurídico a fixação da educação como bem público. No qual seu intuito é assegurar o pleno desenvolvimento da pessoa e o seu preparo para o exercício da cidadania, que é um dos pilares da República Federativa do Brasil, conforme enunciado em seu artigo 205. (COUTINHO, 2007).

Nada que alterasse os ditames e diretrizes da ordem econômica do mercado, mesmo enunciado e estabelecido pela Carta Magna, pouco mudou frente à força do mercado, que continua ditando as regras do ensino técnico e escola como mercadoria de negócios, gerando novos lucros e investimentos. (COUTINHO, 2007). 
Compreendemos a magnitude do papel fundamental que a escola exerce em seus diferentes níveis e modalidades - assumindo o seu devido papel formador e norteador para a formação cidadã e democrática, este caminho se efetiva obrigatoriamente pela garantia e afirmação teórica e prática dos direitos humanos. (CANDAU, 1995).

Devido à demanda de trabalhadores polivalentes no mercado, a sustentação curricular brasileira, está fixada na ideologia de flexibilização com foco marcante na interdisciplinaridade e contextualização do profissional, tornando-o, apenas um trabalhador de manuseio produtivo, assentado pelo fazer e não pela transmissão de conhecimentos. (COUTINHO, 2007).

Apesar das contínuas mudanças nos eixos curriculares, mantém-se a prática de formar trabalhadores aptos para o mercado de trabalho, com o intuito predominante de produção, indo de encontro com as políticas públicas estabelecidas no Brasil, que idealiza capacitar o trabalhador como cidadão transformador e consciente de sua função no quadro social. (COUTINHO, 2007).

Visivelmente, pode-se afirmar que a educação no Brasil, converteu-se em um negócio no qual a produtividade, a eficiência laboral e os resultados positivos tornam-se essenciais para a perpetuidade de qualquer escola, onde a competitividade está intrinsecamente ligada à entrada e consolidação de grandes grupos no setor. (FAVA, 2014). Neste aspecto Marshall relata sobre a igualdade: "há limitações inerentes ao movimento em favor da igualdade. Mas o movimento possui um duplo aspecto. Opera, em parte, através da cidadania e, em parte, através do sistema econômico. (MARSHALL, 1967).

No Brasil sempre ocorreu à supremacia dos direitos políticos sobres os direitos sociais, como por exemplo, o sufrágio universal - grande e importante conquista democrática, todavia, acabou corroborando na geração de uma ideia ilusória, do respeito mútuo a todos os cidadãos. (BENEVIDES)

Segundo o pensador italiano Gramsci, a democracia na escola se arquiteta pela superação da dualidade curricular historicamente repassada para os cidadãos, principalmente ao povo brasileiro, que diferenciam os saberes e aprendizados conforme a classe social. Esta construção educacional democrática na escola ocorre em um processo intenso, haja vista, terse a necessidade de ocorrer experiências democráticas internas nas redes de ensino, tais experiências, acarretam na construção e ampliação da consciência democrática dos alunos, derrubando as barreiras autoritárias e hierárquicas construídas historicamente nos espaços sociais. (DRABACH, 2012). 


\subsection{A educação em direitos humanos, no ensino técnico ou profissionalizante contribuiria para a formação cidadã do trabalhador?}

É possível que o maior percalço para o Brasil, não seja somente a questão econômica, mas sim, analisar o Japão e seguir se modelo educacional, do qual, após a derrota na Segunda Guerra Mundial, abarcou o salto qualitativo da educação e a função da escola como fonte de ressurgir e criar empregos, e transformar não apenas homens aptos ao mercado de trabalho, mas sim, cidadãos, proporcionando justiça social e acima de tudo, respeito entre todas as classes. Seguindo essa atitude, o Brasil conseguirá tornar a sua nação mais justa, competitiva e igualitária. (FAVA, 2014).

Diante desta linha de raciocínio, Nadia Pedrotti Drabach ressalta: a construção da gestão democrática da educação no Brasil, apesar dos avanços já conquistados, ainda possui um longo caminho a percorrer no sentido da ampliação dos espaços de vivência democrática. (DRABACH, 2012).

Conforme retrata Benevides, a grande problemática dos direitos humanos reside na sua não-efetividade, sendo que a sua garantia fica submetida à institucionalização de um poder central na sociedade. Os direitos econômicos e sociais são políticas públicas, programas elaborados pelos governos para que venham suprir a necessidade de todos os cidadãos, em especial os grupos carentes e sem posse, seja no contexto de coletividade ou individualizar as necessidades, porém, que ampare todo o conjunto de pessoas. (BENEVIDES, p.8).

É importante ressaltar, que a cidadania democrática é a garantia dos direitos humanos e da dignidade humana e presume a igualdade diante da lei, a igualdade da participação política e a igualdade de condições socioeconômicas básicas. Para efetivar a igualdade, nas condições socioeconômicas, é necessário mais do que a promoção e criação de leis, e sim, a necessidade de realizar ações construtivas visando à aproximação da sociedade com o Poder Público, implantando as políticas públicas formadoras de cidadãos críticos e participativos no âmbito político-social, desenvolvendo processos que permitam utilizar estratégias construtivas incentivando a participação popular efetiva, e assim, amadurecendo e fortalecendo a democracia participativa. (BENEVIDES, p.14).

Neste sentido, o autor Milton Santos ressalta: "cidadão é o indivíduo que tem a capacidade de entender o mundo, a sua situação no mundo e de compreender os seus direitos para poder reivindicá-los” (1997, p.133). (SANTOS, 1997).

Gramsci, sempre analisou a questão da função da escola e seu poder de transformação social. Segundo o estudioso, todas as classes tinham o direito de ter o contato com as ideias que possibilitassem os indivíduos se tornarem cidadãos críticos e ativos, situação que não 
ocorre quando há barreiras entre escola "tradicional" e outra "profissionalizante". (SOUZA, 2010).

Conforme retratado por Gramsci, a divisão fundamental da escola entre escola clássica e profissional tratava-se de um esquema racional manipulador, no qual, a escola profissional se direcionava as classes instrumentais, quanto à escola clássica, destinava-se às classes intelectuais e dominantes. Durante o avanço e desenvolvimento da base industrial, instigava uma forte necessidade de idealizar um novo tipo intelectual urbano.

Deve-se entender que a educação em direitos humanos e cidadania, vão muito além dos muros escolares, pois, ocorrem no convívio social dos indivíduos - no trabalho, na família, na comunidade e em todo seu conjunto. Conforme relata Ana Monteiro Silva, "é trabalhar com a formação de hábitos, atitudes e mudanças de mentalidades, calcada nos valores da solidariedade, da justiça e do respeito ao outro, em todos os níveis e modalidades de ensino". (SILVA, 2000).

Neste aspecto, Maria Benevides ressalta que o Brasil possui uma bela constituição social, e que sem dúvida, representa um grande avanço em relação aos aspectos históricos regado com sangue dos escravos. Todavia, a realidade brasileira vive em constante contradição com os ideais enunciados na Carta Magna. Sabe-se o quão o país foi, e, ainda é marcada pela profunda desigualdade social, devido persistentes políticas oligárquica e da mais escandalosa concentração de renda. (BENEVIDES, p.13).

Para que se efetive essa apropriação de saber, tem-se a necessidade de distribuir a formação educacional democraticamente, visando o cumprimento legal do princípio democrático do direito à educação. Conforme historicidade relatada no Brasil, a negação de tal direito à educação está vinculada com a resistência da classe dominante em repassar o poder de conscientização e transformação que a educação pode acarretar para as classes menos favorecidas. (PARO, 1999).

Desenvolver um modo diferente de pensar e agir da sociedade, desvinculando-se do agir individual, assimilando no cotidiano um senso humanitário e coletivo. Educar é isto, saber a historicidade antecessora e moldar uma identidade de classe nova, independentes intelectualmente e consequentemente - independência econômica em relação às classes dominantes. (SCHLESENER, 2002).

Muito se conquistou com o avanço da integração da rede de ensino, E outro avanço social deve ocorrer com a formação educacional trabalhadora, trata-se, de fomentar a ideologia de inclusão da disciplina de direitos humanos na rede de ensino técnica e profissionalizante. É por meio de políticas públicas, que reavivará uma chama a muito 
apagada pelas ideologias do capital, implantada em todo o sistema educacional e do trabalho, realizando uma nova concepção de pensar e agir crítico aos indivíduos sobre o seu verdadeiro papel social como cidadãos portadores de direitos e garantias, contribuindo para a formação democrática e cidadã da nação brasileira.

Evidenciando ainda mais a necessidade de ir além de apenas garantir o acesso à escola ao povo, mas sim, reavaliar a finalidade da educação e seus objetivos. Trata-se, de contribuir com as novas exigências sociais, a fim de garantir a compreensão sobre a cidadania e direitos humanos, em todas as facetas do mundo fático. Moldando os hábitos e o saber dos indivíduos - embasados em valores solidários, da justiça e do respeito, independentemente do nível de ensino - planejar uma educação voltada a formar a cidadania, capacitando o trabalhador para além da rede de ensino e do mercado de trabalho, ou seja, apto a desenvolver um saber crítico em todas as instâncias do sistema. (SILVA, 2000).

Concebendo que a instrução, e, a capacitação já são fontes de resultados benéficos, somente os estudos mais profundos poderão medir os resultados e os impactos desse processo de formação na vida das pessoas, no que concerne a construção da cidadania. No entanto, anseia-se em ir muito além de apenas capacitar pessoas, e sim, com a inclusão de novas práticas de ensino sobre Direitos Humanos, possam contribuir com a evolução social, principalmente aos jovens estudantes do ensino médio, ou seja, que após a etapa de instrução e capacitação, conquistem os conhecimentos teóricos e metodológicos suficientes para utilizarem em defesa, promoção e respeitos aos direitos humanos. Idealizar atividades educativas e inclusivas no campo dos direitos humanos demonstra aos participantes a importância da cultura de respeito e promoção dos $\mathrm{DH}$, pois é a partir do processo educativo que se transmite a vivencia cultural de um povo ou região de determinado país, transmitindo a ampliação de novas oportunidades de vida e de escolhas. (ROCHA, 2010).

\section{Conclusões}

Os estudos acadêmicos realizados no decorrer do curso provam que devemos partir do princípio que os Direitos Humanos são universais, inerentes e indivisíveis, e depende do Estado juntamente com a sociedade para que realizem ações de ensino, para a efetivação e reestruturação de uma democracia mais justa e solidária. A educação em Direitos Humanos no ensino técnico e profissionalizante fomentará a cidadania do trabalhador, enquanto bem e direito, tanto como a crença na igualdade - como conquista na utopia de todos, que vai avivar todo um conjunto de compromissos em relação à educação e também a Educação em Direitos Humanos. 
O tema do presente trabalho ainda não possui captação e abrangência pela sociedade, haja vista as redes de ensino técnico e profissionalizante, ainda se encontrarem em processo de evolução no país. Ademais, o viés capitalista da sociedade contemporânea enfatiza o lado econômico, mas minora o lado do saber consciente ou saber crítico, moldando homens aptos a produzir e não para pensar.

É complexo abordar o assunto em um mundo cuja ideologia é a incessante busca pelo capital, esquecendo-se de analisar o meio e o modo de conquistar essa estabilidade financeira. Faz-se necessária uma reflexão sobre o que realmente importa ao jovem e ao trabalhador que ingressa no mercado do trabalho, alienar-se ao mundo do capital ou intentar alterar sua realidade, a fim de moldar uma sociedade mais justa e solidária.

Com o presente trabalho, busca-se contribuir com os eixos curriculares atuais das redes de ensino e consequentemente na sociedade, marcadas pelo excesso de produção e a falta de raciocínio. É necessária a efetivação da educação em direitos humanos (SILVEIRA, 2007) nas redes de ensino técnico e profissionalizante que, muito além de capacitar pessoas, devem idealizar novas práticas de ensino, a fim de que os jovens possam conquistar os conhecimentos teóricos e metodológicos suficientes para a defesa, promoção e respeito aos seus direitos. É importante idealizar atividades educativas e inclusivas que demonstrem aos participantes a importância da cultura de respeito e promoção dos direitos humanos, pois é a partir do processo educativo que se transmite a vivência cultural de um povo ou região de determinado país, transmitindo a ampliação de novas oportunidades de vida e de escolhas, contribuindo para a formação democrática e cidadã da cultura brasileira. (ROCHA, 2006).

\section{Referências}

BENEVIDES, Maria Victoria de Mesquita. Democracia e Direitos Humanos - reflexões para jovens. Disponível em: <http://www.dhnet.org.br/dados/cursos/edh/redh/04/4_7_maria_victoria_democracia_dh.pdf > . Acesso em: 09 mai. 2015.

BAEZ, Narciso Leandro Xavier; BARRETO, Vicente. Direitos Humanos em Evolução. Joaçaba: Unoesc, 2007.p 14.

BENEVIDES, Maria Vitoria de Mesquita. Democracia e Direitos Humanos - reflexões para jovens. $\quad$ p.8, $13 \quad-\quad$ 14. $\quad$ Disponível em: 
<http://www.dhnet.org.br/dados/cursos/edh/redh/04/4_7_maria_victoria_democracia_dh.pdf > . Acesso em: 10 mai. 2015.

BOBBIO, Norberto. A Era dos Direitos. Rio de Janeiro: Campus, $11^{\circ}$ edição, 1992. p. 01.

BRASIL, Casa Civil. Diretrizes e bases da educação nacional. Brasília, 1996. Disponível em:< http://www.planalto.gov.br/ccivil_03/Leis/L9394.htm>. Acesso em: 05 mar. 2015.

BRASIL. Ministério da Educação. Educação profissional técnica de nível médio integrada ao ensino médio. Brasília. 2007. Disponível em:<http://portal.mec.gov.br/setec >. Acesso em: 03 out. 2015.

CANDAU, Vera et alii. Oficinas Pedagógicas de Direitos Humanos. Petrópolis, Rio de Janeiro: Vozes, 1995. p.13.

CECATO, Maria Áurea Baroni; et al. Educação em Direitos Humanos: fundamentos teórico-metodológicos. João Pessoa: Universitária, 2007. p. 355.

CIAVATTA, Maria; RAMOS, Marise.Ensino Médio e Educação Profissional no Brasil Dualidade e fragmentação.Revista Retratos da Escola, Brasília, v. 5, n. 8, p. 27-41.2011. Disponível em:<http://www.esforce.org.br/>. Acesso em: 04 set. 2015.

COMPARATO, Fábio Konder. Direitos Humanos no Brasil. Revista USP, São Paulo, 1999, n.43, p.168-175.

COUTINHO, Aldacy Rachid, et al. Educação em Direitos Humanos: fundamentos teóricometodológicos. João Pessoa: Universitária, 2007. p.374 - 375, 379, 382 - 383

DALlari, Dalmo. In; SILVA, Ainda Maria Monteiro. Escola Pública e a Formação da Cidadania: possibilidades e limites. Universidade de São Paulo: Faculdade de Educação. 2000. Disponível em:<http://www.educadores.diaadia.pr.gov.br/>. Acesso em: 09 set. 2015.

DALLARI, Dalmo. Direitos Humanos e Cidadania. São Paulo: Saraiva 1998. p.14 
DRABACH, Nadia Pedrotti, O pensamento de Antônio Gramsci e a gestão da educação pública brasileira. Revista Espaço Acadêmico; n¹38, 2012. p. 64-72.

FAVA, Rui. Educação 3.0. São Paulo: Saraiva, 2014. Disponível em:<http://leitor.editorasaraiva.com.br>. Acesso em: 13 ago. 2015

FORTUNATO, Sarita Aparecida de Oliveira. ESCOLA, EDUCAÇÃO E TRABALHO NA CONCEPÇÃO DE ANTONIO GRAMSCI. PUCPR, 2009. Disponível em:<http://www.pucpr.br/eventos/educere/educere2009/anais/pdf/2015_2166.pdf>. Acesso em: 03 set. 2009.

GRAMSCI, Antonio. In; NOGUEIRA, Marco Aurélio. Gramsci e a escola unitária. Acessa. Disponível em:<http://www.acessa.com/gramsci/?page=visualizar\&id=148>. Acesso em: 03 set.2009

MARSHALL, Thomas Humphrey. Cidadania, Classe Social e Status. Rio de Janeiro: Zahar, 1967. p.61, 109.

PARO, Vitor Henrique. Administração escolar: uma introdução crítica. $8^{\mathrm{a}}$ ed. São Paulo: Cortez, 1999. p.104-105.

PINHEIRO, Flávio Maria Leite. A teoria dos direitos humanos. Disponível em:〈http://www.oab.org.br/editora/revista/users/revista/1242739498174218181901.pdf>. Acesso em: 19 mai. 2015.

ROCHA, José Cláudio; ROCHA, Denise Abigail Britto Freitas. A educação jurídica popular como instrumento deconstrução da educação em direitos humanos. UNEB. Disponível em:<http://www.sepq.org.br/>. Acesso em: 05 out. 2015

RUSSO, Miguel Henrique. In; BAUER, Carlos. et al. Pedagogias Alternativas. Jundiaí, Paco Editorial, 2014.

SACAVINO, Susana Beatriz. Democracia e Educação em Direitos Humanos na América Latina. Petrópolis: Nova América. p. 16, 23 - 24. 
SADER, Emir; Contexto histórico e educação em direitos humanos no Brasil: da $\begin{array}{llllll}\text { ditadura } & \text { à } & \text { atualidade. } & \text { p. } & 76 . & \text { Disponível }\end{array}$ em:<http://www.dhnet.org.br/dados/livros/edh/br/fundamentos/06_cap_1_artigo_03.pdf >. Acesso em: 9 mai. 2015.

SANTOS, Milton As Cidadanias Mutiladas. In: Preconceito. São Paulo: Secretaria da Justiça e da defesa da Cidadania do Estado de São Paulo, 1997.

SCHLESENER, A. H. Revolução e Cultura em Gramsci. Curitiba: Ed: UFPR, 2002.

SILVA, Ainda Maria Monteiro. Escola Pública e a Formação da Cidadania: possibilidades e limites. Universidade de São Paulo: Faculdade de Educação. 2000. Disponível em:<http://www.educadores.diaadia.pr.gov.br>. Acesso em: 11 set. 2015.

SILVA, Juremir Machado da.1964 Golpe Midiático-Civil-Militar. Porto Alegre: Meridional, 2014. p.32.

SILVEIRA, Rosa Maria Godoy, et al. Educação em Direitos Humanos: fundamentos teórico-metodológicos. João Pessoa: Universitária, 2007. p.16, 29 - 33, 36 - 37, 337, 373.

SOUZA, Francinne Calegari de. Educação Profissional: História e Ensino de História. Dissertação (Mestrado em História Social) - Universidade Estadual de Londrina, Londrina, 2010. Disponível em:<http://www.uel.br> Acesso em: 03 set. 2015.

VALLE, Bertha de Borja Reis do, et al. Políticas Públicas em Educação. Curitiba: IESDE S.A Brasil, 2011. p. 137. 